\title{
El Partido Comunista en los albores de la radicalización política en Argentina: estrategia, militancia sindical y antiterrorismo entre 1955 y 1959
}

\section{Ezequiel Murmis}

UBA-conicet

e.murmis@hotmail.com

Title: The Communist Party at the dawn of political radicalization in Argentina: strategy, trade union militancy and anti-terrorism between 1955 and 1959

Resumen: El artículo analiza las posiciones y el accionar del Partido Comunista en la Argentina entre 1955 y 1959, período marcado por la agudización de la lucha de clases tras el golpe de Estado al peronismo. Se estudia el modo en que el PC actuó en el contexto de la dictadura de la "Revolución Libertadora" y el primer año del gobierno radical de Arturo Frondizi, examinando la relación entre la estrategia política, la intervención sindical y su postura antiterrorista ante el crecimiento de la violencia política.

Palabras clave: Partido Comunista de Argentina - movimiento obrero - Resistencia - antiterrorismo

\begin{abstract}
The article analyzes the positions and actions of the Communist Party in Argentina in 1955-1959, a period marked by the aggravation of class struggle after the coup to peronism. It studies the way the Party acted in the context of the dictatorship of the "Revolucion Libertadora" and the first year of the government of Arturo Frondizi, examining the relationship between political strategy, its involvement in labor movement and its anti-terrorist stance with the growth of political violence.
\end{abstract}

Keywords: Communist Party of Argentina - Labor Movement - Resistance Antiterrorism

Recepción: 20 de febrero de 2018. Aprobación: 6 de abril de 2018 .

(Archivos, año VII, $\mathrm{n}^{\circ} 13$, septiembre de 2018, pp. 143-163) 
El escenario social y político abierto en 1955 en Argentina se caracterizó por la agudización de la lucha de clases, en el marco de la mutación del modelo de acumulación capitalista iniciado en el segundo gobierno de Juan D. Perón. El intento de la clase dominante por aumentar la productividad del trabajo y alentar inversiones de capital incluyó un ataque al movimiento obrero para quebrar su resistencia, lo cual fue impulsado por el régimen de facto de la autodenominada "Revolución Libertadora" y plasmado hacia 1959 durante el gobierno radical de Arturo Frondizi.

En este artículo buscamos analizar los lineamientos políticos que guiaron el accionar del Partido Comunista (PC) en un período escasamente estudiado por la historiografia específica, ${ }^{1}$ concretamente entre el golpe de Estado de septiembre de 1955 y enero de 1959, prestando atención a su intervención en el movimiento obrero y sus posicionamientos en torno a la creciente violencia política del período. El recorte temporal obedece al proceso de resistencia llevado a cabo por el movimiento obrero en contra de la aplicación de los planes de aumento de la productividad, la proscripción al peronismo, las intervenciones sindicales $\mathrm{y}$, fundamentalmente, porque fue en ese periodo cuando aparecieron en escena los atentados terroristas como método de lucha. El límite establecido se define por el punto de inflexión producido a principios de $1959^{2}$ cuando, por un lado se modificó la dinámica de la lucha del movimiento obrero tras el desalojo del Frigorífico Nacional "Lisandro de la Torre" y la aplicación del Plan Conintes; y por otro, por el parteaguas que significó la Revolución Cubana al demostrar que la revolución socialista por vía armada era una posibilidad concreta en el continente y que una experiencia heterodoxa en los cánones del marxismo podía triunfar. Esta situación implicó una revisión programática y estratégica en las izquierdas a nivel nacional y latinoamericano.

¿Cuáles fueron las bases programáticas del PC y sus principales caracterizaciones durante la "Revolución Libertadora" y el gobierno de Frondizi? ¿Qué posiciones asumió ante la creciente violencia po-

1. Un análisis político del PC a fines de los 50 se encuentra en Camarero (2014) y Campione (2007), así como en el estudio sobre la "nueva izquierda" de Tortti (1999). Existe en paralelo bibliografia acerca de la cultura y la intelectualidad comunista que recorre los años estudiados, cuyos trabajos centrales son los de Burgos (2004), Massholder (2013), Prado Acosta (2015) y Petra (2017).

2. Este punto es objeto de debate: según James (2006), en 1959 se produjeron una serie de derrotas para la clase obrera en tanto los principales gremios en conflicto fracasaron en la conquista de sus demandas, lo cual abrió el camino -represión e intervenciones sindicales mediante- hacia la aplicación del programa desarrollista; por su parte, Schneider (2005) considera que dicha derrota no fue tal, no sólo porque el movimiento obrero no dejó de combatir en un contexto defensivo, sino porque el empresariado no habría podido lograr sus objetivos en materia de productividad. 
lítica, expresada en los sabotajes y atentados a partir de 1956? ¿Qué características tuvo su intervención en la búsqueda por reorganizar y conquistar un movimiento obrero intervenido y con el peronismo proscripto? Intentaremos responder a estas preguntas recurriendo a fuentes partidarias como la revista teórica mensual Nueva Era, el semanario Nuestra Palabra y las Declaraciones e Informes del Comité Central (CC) y sus principales dirigentes en el período mencionado.

El golpe de Estado iniciado el 16 de septiembre de 1955 contra el gobierno de Juan D. Perón, encabezado por grupos de la Marina, la Aeronáutica y el Ejército, contó con el apoyo de los principales partidos políticos antiperonistas (la Unión Cívica Radical -que en 1956 se dividió en UCR del Pueblo y UCR Intransigente-, el Partido Demócrata, el Partido Demócrata Progresista, el Partido Socialista, el Partido Demócrata Cristiano y Unión Federal), la Iglesia y comandos civiles. La autodenominada "Revolución Libertadora", que gobernó hasta mayo de 1958 con las presidencias de Eduardo Lonardi primero y de Pedro E. Aramburu luego, se constituyó como una dictadura cívico-militar que perseguía objetivos económicos y políticos de largo alcance.

En el plano económico, pretendía llevar a cabo los planes de racionalización y aumento de productividad iniciados bajo el gobierno de Perón con la negociación colectiva de 1954 y el trunco Congreso de la Productividad y el Bienestar Social de 1955. Esa orientación se sintetizó en el Plan Prebisch, basado en la expansión del crédito internacional, el control de la balanza de pagos, la sujeción del aumento de salarios a los aumentos de productividad, la devaluación monetaria, el estímulo a la producción agropecuaria, la promoción de la inversión privada extranjera y la ampliación de la industria siderúrgica, metalúrgica y mecánica.

A nivel político, el gran objetivo era el de refundar la democracia extirpando al peronismo de la vida política. En ese sentido decretó la disolución del Partido Peronista en sus dos ramas (decreto $n^{\circ} 3.855$ ), la inhabilitación para desempeñarse en cargos públicos y direcciones politicas a personas que lo hubieran hecho durante el peronismo $\left(\mathrm{n}^{\circ}\right.$ 4.258) y la prohibición de la propaganda peronista y sus simbolos $\left(\mathrm{n}^{\circ}\right.$ 4.161). A su vez, el gobierno de facto derogó la Constitución de 1949 y buscó replantear el orden político con una reforma constitucional en 1957 que creara un sistema parlamentarista e instaurara el sistema electoral de representación proporcional (Spinelli, 2005).

Estos proyectos ambiciosos se desplegaron de manera inescindible tras la asunción de Aramburu al poder -el 14 de noviembre de 1955con una política de intervención al movimiento obrero en todos sus 
niveles, en la que se combinaban la desperonización y el ataque a las organizaciones sindicales de cara a la negociación colectiva de 1956 en el marco de la mutación del modelo de acumulación de capital. Para llevar a cabo este programa, el gobierno se valió de diversas disposiciones represivas del Estado como la declaración de estado de sitio, la limitación del derecho a huelga ( ${ }^{\circ}$ 10.956), la aplicación de la ley de Residencia $\left(\mathrm{n}^{\circ} 4.144\right)$ y la ley de organización de la nación para tiempos de guerra desde tiempo de paz $\left(\mathrm{n}^{\circ} 13.234\right),{ }^{3}$ entre otras.

En el período 1955-1959, el PC actuó siguiendo su programa establecido en 1928 y los lineamientos fundamentales de su táctica frentista. Si bien adoptó en sus orígenes los estatutos y programas de la Internacional Comunista, que impulsaba la creación de partidos obreros de vanguardia para intervenir en la lucha de clases, tomar el poder por la vía insurreccional e instaurar la dictadura del proletariado, en el VIII Congreso partidario de 1928 estableció caracterizaciones que alteraron su estrategia. Alli se definió al capitalismo nacional como insuficiente y deformado por la dependencia al imperialismo anglo-norteamericano, el peso del latifundio y los resabios semifeudales, lo cual determinó el carácter de la revolución a venir como etapa previa a la revolución socialista: una revolución democrático-burguesa agraria y antiimperialista bajo la dirección del proletariado y su vanguardia (Camarero, 2007). Afianzado este planteo con la adopción de la táctica de Frente Popular a partir de 1935, el PC consideró que la clase obrera poseía aliados en la burguesía nacional desligada de los terratenientes y los capitales extranjeros y configuró entonces el instrumento político para llevar a cabo la mencionada revolución democrático-burguesa: el Frente Democrático Nacional (FDN). Aunque la historia del FDN no puede construirse de manera lineal en la historia del comunismo vernáculo, lo cierto es que a pesar de las adecuaciones coyunturales, esta orientación general se mantuvo hasta $1986 .{ }^{4}$

El estudio de la intervención del PC en estos años debe incluir dos aspectos de la historia del movimiento comunista internacional. En primer lugar, la creación del Kominform en 1947 -que tuvo su impacto con la delimitación de los dos campos antagónicos: el imperialista y antidemocrático y el antiimperialista y democrático- estableció como tarea fundamental de los Partidos Comunistas la "lucha por la paz" para resistir a la expansión imperialista en todos los terrenos. En función de esa estrategia se creó el Movimiento por la Paz, cuya sede local funcionó a partir de 1949 con el nombre de Comité Argentino por la Paz y contó

3. Ésta ley fue un sostén legal del Plan Conintes (Chiarini y Portugheis, 2014).

4. Véanse análisis del FDN en la década peronista (Staltari, 2014), el período 19551963 (Camarero, 2014) y en la última dictadura militar argentina (Casola, 2015). 
con el compromiso de intelectuales extrapartidarios y la Secretaria General del cuadro comunista Ernesto Giudici. A pesar de la orfandad organizativa del Movimiento tras la disolución del Kominform y de la deslegitimación sufrida con los sucesos en Hungría en 1956, el Comité siguió funcionando en el país de manera inercial hasta los años $80(\mathrm{Pe}-$ tra, 2017). En segundo lugar, el XX Congreso del Partido Comunista de la Unión Soviética (PCUS) realizado en febrero de 1956 fue un proceso de cambios estratégicos y doctrinales en relación a los postulados del Kominform. Tras la muerte de Iósif Stalin, en el contexto del crecimiento del campo socialista y los procesos de liberación en Asia, en 1956 se inició la crítica al culto a la personalidad, se habilitó la pluralidad de vías al socialismo según las particularidades nacionales, se esbozó la vía parlamentaria y se promovió la coexistencia pacífica con el bloque capitalista (Marcou, 1981).

El análisis de las fuentes partidarias muestra que la política de paz fue una consigna central en todo el período analizado. En el $38^{\circ}$ aniversario del PC argentino se manifestaba claramente que

los pueblos no quieren la guerra ni fría ni caliente. Por eso intensifican la lucha contra todo lo que tienda a facilitarla. Los pueblos quieren la paz y están decididos a apoyar activamente la política de los que, como la Unión Soviética y demás países del campo socialista, tienden a consolidarla. ${ }^{5}$

En lo respectivo al "deshielo" de la Guerra Fría, el PC vernáculo se apropió de las nuevas definiciones de manera lineal y acrítica (Piemonte, 2013), lo cual quedó demostrado en julio de 1956 en el informe presentado por el secretario general Victorio Codovilla al CC del PC, en el que se señalaba que "es posible realizar la revolución socialista por vía pacífica, sin insurrección armada, utilizando para ese fin el Parlamento" (1964a:185).

En el plano nacional, la sucesión de golpes de Estado imponía como primera tarea la conquista de un régimen democrático, determinando el camino al socialismo del siguiente modo:

Primero, conquistar el régimen democrático, y luego desarrollar la democracia "hasta el fin", o sea, hasta resolver los problemas de la revolución democrática, agraria y antiimperialista, a fin de abrir un camino luminoso para nuestra clase obrera, nuestro pueblo y nuestra nación, que desemboque en el socialismo. (1964a: 197)

5. "El $38^{\circ}$ aniversario del Partido", Nueva Era, año VIII, n 1 , enero de 1956, p. 2. 
Como mencionamos, el instrumento para llevar a cabo la revolución democrática era el FDN que reúna al PC con "todas las fuerzas patrióticas, democráticas y progresistas del país [...] [en la] lucha por la independencia nacional, las libertades democráticas, el bienestar social y la paz". 6

La instauración de la "Revolución Libertadora" fue analizada por el $\mathrm{CC}$ del PC en una Declaración que afirmaba el principio de oposición a "todo golpe de Estado". Alli se exponía que, en el marco de la guerra civil desatada entre el gobierno peronista y los partidarios del golpe luego del levantamiento militar, la tarea consistía en la formación de un FDN para establecer un gobierno de coalición que asegurase la convivencia democrática. A pesar de la principal crítica que dirige a ambos sectores, concerniente a la exclusión del pueblo para la solución de los problemas del país, el PC mostró una posición expectante ante la situación abierta con el Gobierno Provisional. Consideraba que éste, amén de haber sido orquestado por la oligarquía terrateniente, el gran capital, el alto clero y el imperialismo yanqui, tenía una composición heterogénea donde convivian sectores que "aspiran de veras a un régimen auténticamente democrático y progresista" y sectores reaccionarios que defendian los intereses de los promotores del golpe. La política del PC consistía entonces en reunir a las fuerzas democráticas, progresistas y antiimperialistas en un FDN para imponer al sector democrático las reivindicaciones populares, razón por la cual llamó a que "esas fuerzas estén vigilantes y demuestren [...] su disposición a apoyar todo paso que las nuevas autoridades den en el sentido indicado, así como su decisión de combatir toda medida de contenido reaccionario". ${ }^{7}$

En ese sentido, uno de los apoyos que brindó el PC al gobierno de Aramburu fue el pronunciamiento a favor -a pesar de su fracaso- de la modificación del sistema electoral basado en la representación proporcional, punto en el que coincidió con los partidos antiperonistas radicalizados (el Partido Socialista y el Demócrata Progresista) en el marco de la convocatoria de la Asamblea Convencional Constituyente en 1957 (Spinelli, 2005).

Además de la oportunidad que significaba el golpe de 1955 para desmontar el "Estado de tipo corporativo-fascista", se abría también la posibilidad de ganar a trabajadores y trabajadoras peronistas tras una década de haber perdido terreno en el movimiento obrero. Para lograrlo el PC buscó demostrar que el peronismo utilizó la demagogia

6. Idem, p. 5.

7. “¿Hacia dónde marcharán los acontecimientos? Declaración del CC del PC después del reciente levantamiento militar y la constitución del gobierno provisional", Nuestra Palabra, $\mathrm{n}^{\circ}$ 282, 27 de septiembre de 1955, pp. 1-4. 
social "para desviar a las masas trabajadoras del camino de la lucha independiente en la defensa de sus intereses"8 mientras mantenía la estructura económica semifeudal del capitalismo latifundista argentino y garantizaba la entrega de las riquezas nacionales al capital extranjero.

Sin embargo, esto no debe interpretarse como una posición de apoyo unívoco al golpe. Por un lado, el PC no compartía la política de proscripción al peronismo: ya en la Declaración citada reclamaban el "amplio ejercicio de las libertades públicas de los partidos políticos, de las organizaciones sindicales y sociales, sin restricciones ni discriminaciones" y que "renuncien a las persecuciones contra los peronistas por su actividad política o social pasada o presente". ${ }^{9}$ Luego, en ocasión de la disolución del Partido Peronista en sus dos ramas a fines de 1955, se opuso a la medida a pesar de las diferencias con el peronismo y afirmó defender "el derecho de los ciudadanos peronistas, hombres y mujeres, a militar en el partido político que más les guste". ${ }^{10}$ Finalmente, expresó el mismo enfoque durante el gobierno de Frondizi, cuando se denegó la personería al Partido Peronista en agosto de $1958 .{ }^{11}$ Por otro lado, el PC denunció a lo largo del período la política económica de facto sintetizada en el Plan Prebisch, que fue interpretado como la continuación de las politicas aplicadas hacia el final del peronismo y tendiente a descargar la crisis sobre los hombros de la clase obrera al incrementar la carestía de vida, la desocupación y buscar aumentar la productividad. Entendida como el complemento del Plan Prebisch, ${ }^{12}$ la política de intervención en los distintos niveles del movimiento obrero fue el principal motivo de enfrentamiento con la "Revolución Libertadora".

\section{2}

La ofensiva de la "Revolución Libertadora" fue enfrentada por sectores de la clase obrera que protagonizaron la Resistencia. Este fue un fenómeno de impugnación social que asumió diversas características al actuar sin una dirección clara y centralizada (Schneider, 2005). Si bien suele calificársela como "peronista" (James, 2006; Salas, 1990; Amaral, 2004), participaron distintos sectores con programas y acciones disimi-

8. Idem, p. 2.

9. Ibídem.

10. "Los ciudadanos peronistas tienen derecho a militar en el Partido que más les guste", Nuestra Palabra, n 292, 6 de diciembre de 1955, p. 3.

11. "Los ciudadanos peronistas tienen derecho a actuar con su propio partido", Nuestra Palabra, n 429, 28 de agosto de 1958, p. 1.

12. "Altiva y dispuesta a ganar su independencia y unidad, volvió al trabajo la clase obrera", Nuestra Palabra, n 290, 22 de noviembre de 1955, p. 1. 
les, conviviendo de manera desordenada los sabotajes a la producción, ataques terroristas, levantamientos militares y la actividad sindical en la reorganización del movimiento obrero intervenido.

El carácter inorgánico y espontáneo de la Resistencia estuvo dado por la ausencia de una dirección sindical y política en condiciones de organizar la oposición al régimen (Schneider, 2005: 78). Por un lado, fuera del poder y con el líder exiliado se complejizaron las redes de poder del peronismo polimorfo. La cúpula del Consejo Superior Peronista con Alberto Teisaire al mando acusó de delitos al peronismo y se distanció de Perón inmediatamente, así como surgieron partidos neoperonistas que buscaron capitalizar la ausencia de liderazgo (Melon Pirro, 2009). En simultáneo, durante el gobierno de Lonardi, la CGT dominada por el peronismo accedió a dialogar con éste, abandonando a los sectores de las bases obreras que pretendian luchar contra el nuevo régimen. ${ }^{13}$ Esa situación se manifestó en las jornadas del 17 de octubre y el 3 de noviembre de 1955, cuando la dirigencia sindical exhortó a las bases a concurrir al trabajo, llamado que fue desconocido por importantes franjas del proletariado industrial (Schneider, 2005; James, 2006).

El PC buscó delimitarse de la dirigencia sindical peronista que se mantenía al frente de la CGT, a la que consideraban un resabio de la política verticalista instrumentada por el peronismo, cuya autonomía se encontraba lesionada. A su vez, entendía que su marcada orientación política promovía la división precisamente cuando el PC propiciaba la política unitaria en pos de la consolidación de un régimen democrático. Los "jerarcas" de la CGT fueron acusados durante el lonardismo de traicionar los intereses obreros ${ }^{14} \mathrm{y}$ entablar acuerdos con el gobierno en el marco de lo que el PC interpretaba como una política intervencionista en los gremios. ${ }^{15}$ Las diferencias de acción con dicha dirigencia se expresaron hacia fines de 1955 en ocasión de la amenaza de huelga general realizada por la CGT tras el decreto gubernamental que fijaba las pautas para la celebración de las elecciones en la CGT. En esa ocasión el PC se manifestó en contra de la huelga en tanto el objetivo de

13. La entente entre la CGT y el gobierno presentaba dos aristas: tras la ocupación de sindicatos por la fuerza, el gobierno se comprometía a realizar elecciones sindicales en un plazo de 120 dias, respetando sus estatutos y la ley de Asociaciones Profesionales; a cambio, el acuerdo del 6 de octubre de 1955 indicaba que se eliminara el preámbulo partidario de la Doctrina Justicialista del estatuto adoptado por la CGT en 1950 y que se renovaran las autoridades, lo cual se formalizó con el nombramiento de Luis Natalini y Andrés Framini al frente de la CGT (Senén González, 1971: 11).

14. “¿Hacia dónde marcharán los acontecimientos? Declaración...”, Nuestra Palabra, $\mathrm{n}^{\circ} 282,27$ de septiembre de 1955, p. 3.

15. “iUnidad obrera frente al decreto de intervención a los gremios!”, Nuestra Palabra, $\mathrm{n}^{\circ} 288,8$ de noviembre de 1955 , p. 6 . 
la misma "sería el de mantener a los jerarcas intocables en la dirección del movimiento sindical y apoyarlos en el pacto que establecieron con el gobierno". ${ }^{16}$ Aunque a mediados de noviembre participaron de la huelga general -que fuera luego ilegalizada-convocada por la CGT en el marco de la asunción de Aramburu, las denuncias contra la dirigencia peronista no cesaron: fue acusada de realizar el paro con el objetivo de pactar acuerdos con el gobierno a espaldas de las bases trabajadoras. ${ }^{17}$

La llegada de Aramburu al poder puede explicarse por la combinación entre la falta de acuerdo en el interior de la alianza antiperonista en lo referente a la desperonización y el rol de los partidos políticos (Spinelli, 2005) y por la acción de las bases obreras en el marco de los acuerdos entablados por la dirigencia sindical con el gobierno y la ocupación de los sindicatos por los comandos civiles ligados a la UCR y el PS (Schneider, 2005). El recrudecimiento de la situación dada por la intervención del movimiento obrero y los intentos de aumentar la productividad intensificó la lucha de clases en el contexto de la Resistencia.

Como señalan James (2006) y Melon Pirro (2009), los sabotajes en los lugares de trabajo eran las primeras respuestas espontáneas e inorgánicas en contra de la implementación de los planes de racionalización reunidos en el decreto 2.739 de febrero de $1956 .{ }^{18}$ Los sabotajes entraron en un agotamiento progresivo a partir de abril de ese año dando lugar a hechos terroristas basados en la utilización de explosivos primitivos contra objetivos específicos. Los atentados perduraron en 1957 y no parecieron estar en relación directa con los crecientes conflictos sindicales, los cuales pasaron a primer plano a partir de 1956-1957. Si bien convivieron, mientras los grupos irregulares e inorgánicos del peronismo practicaban sus acciones en la clandestinidad con escasa relación, el movimiento obrero en proceso de reorganización buscaba adquirir y consolidar espacios de legalidad (Melon Pirro, 2009).

A lo largo del período 1955-1959, el PC repudió enfáticamente los atentados y sabotajes como método para luchar contra la "Libertadora". ${ }^{19}$

16. "Frente al decreto-ley ¡unidad, democracia e independencia sindical!", Nuestra Palabra, $\mathrm{n}^{\circ} 287,1$ de noviembre de 1955, p. 7 .

17. "Altiva y dispuesta a ganar su independencia y unidad, volvió al trabajo la clase obrera", Nuestra Palabra, no 290, 22 de noviembre de 1955, pp. 1-2.

18. Se prorrogó la vigencia de los convenios colectivos hasta la homologación de los que se establecieran en su reemplazo; concedió un aumento del $10 \%$ sobre los salarios percibidos al 31 de enero de 1956; derogó las cláusulas que no convenían a la superexplotación; incorporó incentivos para la intensificación del trabajo y la movilidad en la fábrica; promovió la realización de horas extra y dio rienda libre para los criterios de promoción, que dejaban sin efecto la antigüedad y estructuraban un régimen meritocrático.

19. En el PC existió un "Frente de Autodefensa" de carácter clandestino dedicado al 
Declarándose "enemigo del terrorismo y de los atentados", ${ }^{20}$ denunció que los mismos eran utilizados por elementos enrolados en una campaña anticomunista alentada por el imperialismo yanqui. Contra esa "infame maniobra" sostuvieron:

La lucha de los comunistas no consiste en el sabotaje ni en actos de terrorismo, que nuestro Partido rechaza por principio. La lucha de los comunistas es la lucha por la unidad de acción de todos los sectores democráticos, para conquistar la solución progresista, patriótica, de los graves problemas que afectan al país. Precisamente por esto es que los comunistas estuvimos ayer contra los actos terroristas y contra los golpes de Estado, y seguimos estando hoy contra los actos terroristas y contra los golpes de Estado. ${ }^{21}$

En sintonía con esa declaración, afirmaron que "desde su aparición en la vida política nacional [...], ni el atentado individual ni el sabotaje ni el golpe de Estado, fueron los métodos de lucha de nuestro partido; no solamente no los practica sino que los condena en forma explícita". ${ }^{22}$

La acusación de "sabotaje a la productividad" fue moneda corriente para allanar el proceso de racionalización a través de despidos y detenciones, ${ }^{23}$ razón por la cual el PC buscaba eliminar los pretextos sobre

entrenamiento militar, aunque no estaba destinado a la preparación de enfrentamientos de violencia armada de masas sino para la defensa de las manifestaciones por reivindicaciones. Se preparaban para, por ejemplo, repeler la represión con tácticas de rompimiento de filas y puntos de concentración y desconcentración o proteger la toma de un establecimiento (Nadra, 2015). El campamento de entrenamiento en Icho Cruz en 1964 podría formar parte de la actividad de ese Frente (Rot, 2007). Otras experiencias de actividad militar del PC argentino se remontan a los '30, como las Brigadas internacionales en la Guerra Civil española, la participación en la insurrección de 1935 en Brasil liderada por Luis Prestes o la llamada "primera guerrilla del siglo XX" instalada circa 1938 en Chaco (Gilbert, 2009; Nadra, 2015).

20. "Esta es la verdad", Nuestra Palabra, n 317, 20 de junio de 1956, p. 3.

21. "Una infame maniobra", Nuestra Palabra, n 302, 29 de febrero de 1956, p. 1.

22. "Declaración del C. Central del P. Comunista acerca de recientes manifestaciones del M. del Interior a una agencia extranjera”, Nuestra Palabra, $n^{\circ}$ 305, 21 de marzo de 1956, pp. 4-5.

23. En Nuestra Palabra: "Cesantías, despidos y superexplotación. Lo que se cumple y lo que no se cumple. Las mejoras de sueldos y salarios", $\mathrm{n}^{\circ} 306,28$ de marzo de 1956, p. 7; "Coordinan su acción nacional los obreros de la carne", n 307, 4 de abril de 1956, p. 6; "iAlerta contra los despidos! Dicen los ferroviarios rosarinos a la clase obrera de todo el país", $\mathrm{n}^{\circ} 308,11$ de abril de 1956, pp. 1-2; "Noticias obreras", n' 310, 25 de abril de 1956, p. 6; "Noticias obreras", $\mathrm{n}^{\circ}$ 311, 2 de mayo de 1956, p. 6; "Sigue la huelga de la Construcción en Córdoba", n 318, 27 de junio de 1956, p. 7; 
los cuales se asentaban esas maniobras. De hecho, advirtió que existian casos en los que las acciones eran cometidas por elementos adictos al gobierno para encarcelar a luchadores y luchadoras. ${ }^{24}$

La postura del PC ante los sabotajes y atentados estaba ligada a los planteos basados en la construcción de un FDN hacia el establecimiento de un Gobierno de Coalición Democrática en condiciones pacíficas, que se encontraba a su vez en sintonía con las definiciones del XX Congreso del PCUS. Sostuvo que "un clima de auténtica democracia es la mejor garantía contra el sabotaje y la provocación terrorista" 25 y buscó distanciarse de los "provocadores, terroristas y saboteadores" al tiempo que establecía una distinción entre "los grupos minúsculos" que cometían estos actos y la clase obrera en sí misma. ${ }^{26}$ Buscó entonces aislar a esos grupos, afirmando que "es cierto que la aventura terrorista existe. Pero es totalmente falso que las luchas obreras por reivindicaciones sobradamente conocidas formen parte de ese complot, como también es falso que los comunistas participen del mismo"; ${ }^{27}$ y promovió que fuera la justicia la encargada de actuar sobre los responsables, en tanto "el pueblo repudia los sabotajes, pues los mismos afectan a la economía nacional y perturban la tranquilidad pública. Los saboteadores merecen el rigor de la ley". 28

La intervención del PC durante la Resistencia estuvo centrada en la actividad sindical, en donde las dos principales luchas fueron en torno a las condiciones de trabajo (cuyos ejes fueron las pautas de la negociación colectiva y los despidos) y la reorganización del movimiento obrero intervenido. Se trató de dos procesos inescindibles en tanto la reorganización del movimiento obrero en resistencia se estructuró a raíz de la conformación de Comisiones Paritarias en 1956 y el llamado a elecciones -entre julio y septiembre de ese año-de comisiones internas y comisiones directivas de los sindicatos.

La política de FDN que el PC construyó en los sindicatos a través de su organización sindical -el Movimiento Pro Democratización e

\footnotetext{
"Por las 7 hs. y por un mínimo de $\$ 1.800$ se pronuncian en IAME", n 328, 5 de septiembre de 1956, p. 7; "El incendio de SIAM", n 342, 26 de diciembre de 1956, p. 4. 24. "Denuncia de la Liga Argentina por los Derechos del Hombre. Graves torturas en Córdoba", Nuestra Palabra, n 313, 16 de mayo de 1956, p. 3; "Están al descubierto los que organizaban los sabotajes", Nuestra Palabra, n 327, 29 de agosto de 1956, p. 4. 25. "Una infame maniobra", Nuestra Palabra, n 302, 29 de febrero de 1956, p. 1. 26. "Declaración del C. Central del P. Comunista...", Nuestra Palabra, n 305, 21 de marzo de 1956, pp. 4-5.

27. "La aventura y la clase obrera", Nuestra Palabra, no 342, 26 de diciembre de 1956, p. 4.

28. “Cifra: 15.000 presos", Nuestra Palabra, n 354, 20 de marzo de 1957, p. 3.
} 
Independencia de los Sindicatos- estuvo caracterizada por el armado de comités unitarios de lucha en los lugares de trabajo, cuyo objetivo era unir a trabajadores y trabajadoras sin distinciones politicas ni religiosas. ${ }^{29}$ En la convocatoria a elecciones sindicales, su propuesta consistió en el armado de listas unitarias en los gremios, con el objetivo de recuperar los sindicatos intervenidos y encaminar el proceso hacia la normalización de la CGT. Las elecciones llevadas a cabo entre 1956 y 1957 definieron los principales bastiones del PC: participó en las listas que obtuvieron la dirección de los sindicatos de Químicos, Construcción, Músicos, Vendedores de diarios, Gastronómicos de Capital, Prensa, Aceiteros y Madera.

La presencia comunista en el movimiento obrero cobró relevancia a partir de 1957 al convertirse en el principal organizador del primer nucleamiento intergremial luego de la intervención de la CGT: la Comisión Intersindical (CI) ${ }^{30}$ En su acta de nacimiento, representada en el memorial al Presidente del $1^{\circ}$ de marzo de 1957 firmado por las 21 organizaciones normalizadas adheridas, ${ }^{31}$ expuso el programa de 5 puntos que guió el accionar del movimiento obrero hasta la asunción de Frondizi. El mismo reunía los grandes reclamos del sindicalismo durante la dictadura: a) libertad de los trabajadores presos y confinados sin causa y sin proceso, la no aplicación de la ley 4144 a Eduardo Seijo, Antonio Losada y demás obreros en las mismas condiciones; b) normalización del movimiento obrero mediante el levantamiento de todas las intervenciones y la convocatoria a elección en los sindicatos que restan, en las Federaciones Nacionales y en la CGT; c) restablecimiento de precios máximos para los artículos de primera necesidad y control de las maniobras especulativas de toda índole y la elevación arbitraria de los mismos; d) que se garanticen las libertades y derechos sindicales mediante el levantamiento del estado de sitio y la vigencia de los derechos de huelga, prensa, reunión y palabra, como paso decisivo hacia la normalización institucional; e) derogación de leyes, decretos y resoluciones restrictivas de los derechos obreros y la ley 4144 .

La CI creció al calor de la normalización de los sindicatos y extendió su influencia inicial en Capital y Gran Buenos Aires a diversos puntos del interior con la creación de Comisiones Regionales (Íscaro, 1973).

29. "Organizar comisiones unitarias", Nuestra Palabra, n ${ }^{\circ}$ 310, 25 de abril de 1956, p. 4.

30. Aunque no fue analizada en detalle, la importancia del PC como organizador de la misma se menciona en James (2006), Salas (1990), Schneider (2005) y Melon Pirro (2009).

31. "21 gremios apoyan a la Comisión Intersindical", Nuestra Palabra, n 352, 6 de marzo de 1957, p. 3. 
Liderada por el sindicalismo comunista y secundada por los sindicatos obtenidos por peronistas, la CI ocupó el espacio de la CGT intervenida y fijó su autodisolución precisamente con la normalización de la misma. Presión mediante, ${ }^{32}$ logró que el interventor de la central, Alberto Patrón Laplacette, convocara al Congreso Normalizador de la CGT para agosto de ese año: aún con reservas, las organizaciones adheridas a la CI participaron del mismo dándole un duro golpe a la "Revolución Libertadora".

El Congreso Normalizador fue el escenario sobre el cual el gobierno fracasó en su intento por imponer una dirección sindical que le fuera afin, representada en el llamado "sindicalismo libre" ligado al radicalismo y el Partido Socialista. Alli se produjo una alianza entre el sindicalismo comunista y peronista, cuando mantuvieron quorum ante el retiro de los 32 gremios del sindicalismo libre en la discusión en torno a la verificación del número de afiliados de las organizaciones y su correspondiente representación en el Congreso (Gasparri y Panella, 2008). Así nacieron los agrupamientos sindicales que predominaron en los años siguientes: por un lado, los "32 Gremios Mayoritarios y Democráticos"; por otro, las "62 Organizaciones" de mayoría peronista y minoría comunista. Se inició así una breve convivencia entre peronistas y comunistas en la Mesa Coordinadora de las 62 que, con la progresiva reconstrucción del poder peronista en el movimiento obrero, derivó en el alejamiento del PC y la creación de su propio agrupamiento sindical a fines de 1958: el Movimiento de Unidad y Coordinación Sindical (MUCS).

El fracaso de la política de desperonización del movimiento obrero se combinó con el fallido intento de reforma del sistema político en la Asamblea Constituyente, razones por las cuales -en un contexto de alta conflictividad- la "Revolución Libertadora" preparó una salida electoral para febrero de 1958 con el peronismo proscripto. En términos políticos, el nuevo equilibrio inestable que nació con el triunfo del radical intransigente Arturo Frondizi fue el integracionismo, basado en el intento de establecer una alianza de clases que permitiera la implementación del programa económico desarrollista. La principal orientación de éste se encontraba en la sustitución de trabajo por capital en la producción industrial (Portantiero, 1977), un cambio en la estructura productiva que debía realizarse con el financiamiento de capitales extranjeros, el

32. "Plenario Nacional para el 10 de junio", Nuestra Palabra, $\mathrm{n}^{\circ}$ 365, 29 de mayo de 1957, p. 4. 
crédito internacional y el recurso a la libre empresa, especialmente en las áreas de petróleo, gas, siderurgia e industria química.

La fórmula Frondizi-Gómez accedió al poder con el imprescindible apoyo del peronismo -tras el acuerdo con el propio Perón-, las 62 organizaciones, el PC, el trotskismo e intelectuales progresistas. La alianza con el peronismo fue un punto central del proceso en tanto permitía integrar al movimiento obrero en el compromiso con el sector que buscaba construir hegemonía: la gran burguesía industrial ligada al capital extranjero (Portantiero, 1977). La integración se plasmó en el acuerdo de una ley de Asociaciones Profesionales para que el peronismo volviera a controlar el movimiento obrero. ${ }^{33}$ No obstante, el acuerdo entre el gobierno y la dirigencia sindical peronista -que debilitó las luchas obreras durante $1958-^{34}$ se quebró en la medida en que avanzó la aplicación del plan económico.

En las elecciones el PC presentó sus propios candidatos para el Congreso, Legislaturas y Concejos Deliberantes, y apoyó la fórmula presidencial de la UCRI tras fracasar en su intento de conformación del FDN junto a la UCRI, la UCR del Pueblo, el Partido Socialista, el Demócrata Cristiano, el Laborista y el dirigido por Alejandro Leloir. El CC del PC consideró que el viejo "Programa de Avellaneda" de Frondizi era aquel que mayor cercanía tenía con el suyo de 5 puntos, basado en

el compromiso de establecer los más amplios derechos democráticos para todos los argentinos nativos y habitantes del país, de garantizar los derechos del trabajador, de defender las riquezas nacionales, sobre todo del petróleo, de dar estabilidad en la tierra a los campesinos y realizar la reforma agraria y practicar una politica exterior independiente que coadyuve al establecimiento de la paz mundial. ${ }^{35}$

Sin embargo, Frondizi no encabezó la esperada lucha contra la oligarquía y el imperialismo, por la defensa de las riquezas nacionales, ni llevó a cabo la reforma agraria. Las esperanzas del comunismo en que el nuevo gobierno asegurara "la independencia nacional para dar solución

33. Antes de asumir, Frondizi pidió una tregua al movimiento obrero en su reunión con la Mesa Coordinadora de las 62 Organizaciones, que fue respondida con un memorial para sentar las bases del acuerdo. "Memorial de "las 62" a Frondizi", Nuestra Palabra, no 407, 27 de marzo de 1958, p. 7.

34. Las 62 Organizaciones no acompañaron el paro convocado para fines de mayo por los 32 Gremios, no pararon el 17 de octubre y hasta debatieron sancionar a los médicos que pararon (Schneider, 2005; 116-118).

35. "La fórmula Frondizi-Gómez es la que ofrece mayor garantía programática", Nuestra Palabra, n 400, 6 de febrero de 1958, p 1 y 8. 
a los problemas de la revolución democrático-burguesa, agraria y antiimperialista" ${ }^{36}$ se fueron desvaneciendo en la medida en que el gobierno se volcó hacia "el abandono del programa progresista de la UCRI y la defensa de los intereses tradicionales de la oligarquía agropecuaria, del gran capital y de los monopolios imperialistas" (Codovilla, 1964b: 370).

El PC consideró que Frondizi pudo abandonar su programa, en primer lugar, porque la amplia mayoria obtenida en las Cámaras del Congreso le permitió dejar atrás las promesas; y, en segundo, porque las masas no ejercieron presión suficiente para imponer sus demandas. Sobre este punto, el PC se refería especialmente al peronismo, que presentó una tregua tras haber negociado el apoyo a Frondizi a cambio de obtener la legalidad del peronismo y la dirección del movimiento obrero.

En la arena sindical, dicha tregua se manifestó en función de la sanción de la Ley de Asociaciones Profesionales ( $n^{\circ}$ 14.455) en agosto de 1958. La misma se basaba en el reconocimiento de un único sindicato por rama, abolía la representación de la minoría en la dirigencia y restablecía el modelo peronista que asignaba a la lista ganadora el control total del sindicato (James, 2006). Este punto de negociación desencadenó el alejamiento del PC de las 62 Organizaciones a fines de año, aunque las tensiones con la dirigencia peronista estuvieron presentes a lo largo de su participación conjunta. El enfrentamiento más importante radicaba en que, en la medida en que el peronismo se fortalecía en ese espacio, el mismo se convertía en un nucleamiento partidario que atentaba contra la unidad sindical (Íscaro, 1973: 341).

El año 1958 siguió siendo un año de conflictos sociales, aunque "las 62" priorizaron negociar espacios de poder en el marco institucional, trazando un quiebre con la actividad desarrollada tanto por ese agrupamiento como por la CI durante 1957. Aun con numerosos sindicatos en proceso de normalización y con la problemática asociada a la carestía de vida, la dirigencia sindical peronista realizó en el año un solo paro general de 24 horas el 10 de octubre y frenó los paros por el día de la lealtad peronista y el programado para los días 20 y 21 de noviembre en la llamada "Batalla del petróleo".

En julio de 1958 el presidente anunció un plan de autoabastecimiento del petróleo a partir del recurso a capitales extranjeros para la extracción del mismo. Esa política condensó una serie de aspectos del complejo entramado que caracterizó a esta etapa de la resistencia.

En primer lugar, allí se manifestaron las diferencias entre un sector de las bases obreras que lucharon en contra de la aplicación de los contratos petroleros con empresas extranjeras y el rol de la dirigencia

36. "Llamamiento del Partido Comunista con motivo de la celebración del $1^{\circ}$ de mayo", Nuestra Palabra, $\mathrm{n}^{\circ} 411,24$ de abril de 1958, p. 8. 
sindical peronista en proceso de integración. En octubre de 1958, la filial Mendoza del Sindicato Unido de Petroleros del Estado (SUPE) inició una huelga por tiempo indeterminado en contra del plan, acompañada por el Sindicato de Gas del Estado de esa provincia. En ese contexto, la dirección nacional del SUPE y las 62 Organizaciones buscaron menguar el enfrentamiento con el gobierno mediante el diálogo. El resultado del conflicto fue la ilegalización de la huelga, la declaración del estado de sitio y la desmovilización de los trabajadores y trabajadoras de Mendoza a través de la presión ejercida por las direcciones sindicales, las cuales cancelaron el paro convocado por las 62 para los dias 20 y 21 de noviembre tras la firma de un convenio para revisar los contratos que terminó siendo rechazado por el propio Frondizi y marcó el alejamiento de Rogelio Frigerio, principal figura del gobierno (James, 2006).

En segundo lugar, a partir de este punto el PC comenzó a pasarse a la oposición al gobierno. Manteniendo el principio de apoyar lo positivo y criticar lo negativo, consideró que el gobierno atacaba el problema del petróleo sin resolver la crisis estructural de la Argentina. Su propuesta era la elaboración de un plan general para solucionar los problemas económicos, cuya tarea en materia petrolera era la nacionalización de los yacimientos y el intercambio de maquinaria necesaria con la Unión Soviética. ${ }^{37}$

Sin embargo, el punto de inflexión fue la campaña anticomunista que se desplegó durante la huelga del SUPE, que culminó en la aplicación del Plan Conintes. En ella, el presidente acusó a comunistas y peronistas de subversivos y, tras la declaración del estado de sitio el 11 de noviembre, inició detenciones a militantes comunistas y peronistas. La Declaración emitida afirmó que:

el anticomunismo ha resultado ser la cortina de humo que se tiende para ocultar el movimiento de las fuerzas reaccionarias representativas de los intereses de la oligarquia terrateniente, del gran capital y de los monopolios extranjeros, tendientes a entregar las riquezas del país, en particular del petróleo, a los imperialistas y a descargar las consecuencias de la crisis sobre las espaldas del pueblo trabajador. ${ }^{38}$

El partido negó formar parte de un plan subversivo con motivo de la

37. "Declaración del CC del PC. 25 de julio de 1958", Nueva Era, año X, n 6, julio de 1958, pp. 3-8.

38. "Acerca de la nueva situación creada en el país", Nueva Era, año X, n 10 , noviembre de 1958, p. 4. 
huelga petrolera por más que sus militantes participaran en la misma ${ }^{39} \mathrm{y}$ responsabilizó al gobierno por su orientación reaccionaria y el abandono del programa prometido en elecciones. Contra la subversión, defendieron el régimen democrático: la salida -reiteraron- era la formación de un FDN para frenar los golpes de Estado a partir del establecimiento de un gobierno de coalición democrática. ${ }^{40}$

Por lo tanto, y en tercer lugar, en esa situación se determinó el estado de Conmoción Interior (Conintes) y la consecuente aplicación del Plan mediante el decreto secreto 9.880 del 14 de noviembre de 1958. En el marco de la Resistencia, el aumento de la conflictividad social y de cara al anuncio del Plan de Estabilización Económica bajo el designio del Fondo Monetario Internacional, el Plan Conintes fue una forma de represión estatal dirigida por las Fuerzas Armadas contra la figura de un enemigo interno que amenazaba los intereses de los sectores dominantes, cuyas acciones eran interpretadas como parte del desarrollo del comunismo internacional. Fue un estado de excepción que, basado en la Doctrina de Seguridad Nacional y la doctrina contrainsurgente del ejército francés, habilitaba medidas igualmente excepcionales en el marco de una guerra revolucionaria o guerra ideológica contra la población fronteras adentro. De este modo, huelgas, sabotajes o atentados se concebían como tácticas de un enemigo de los intereses nacionales en contexto de guerra, al que se identificó con la clase obrera en lucha $\mathrm{y}$, en particular, los sectores peronistas ${ }^{41}$ y comunistas definidos como subversivos (Chiarini y Portugheis, 2014). En las primeras semanas de ejecución, se intervinieron sindicatos en conflicto como la Unión Tranviarios Automotor, la Asociación Obrera Textil, la Unión Obrera de la Construcción (UOCRA), el Sindicato de Obreros y Empleados del Frigorífico Lisandro de la Torre y se movilizó militarmente al personal de Transportes de Buenos Aires, petroleros y ferroviarios.

El PC sufrió la detención de 36 militantes con la declaración del estado de sitio, la intervención de la UOCRA dirigida por los comunistas Rubens Íscaro, José Zárate y Roque Alessi -el 22 de enero de 1959 luego del paro convocado por el MUCS en solidaridad con la lucha del

39. El PC dio cuenta de que "si bien no ocupan puestos de dirección en el SUPE, los comunistas que pertenecen al gremio del petróleo han aprobado y aprueban la decisión de su organización y han hecho y harán lo posible para que tenga éxito". "Declaración del CC del PC sobre la nueva situación que se ha creado después del discurso presidencial y del establecimiento del Estado de Sitio", Nueva Era, año X, $\mathrm{n}^{\circ} 10$, noviembre de 1958, pp. 13-14.

40. Idem, pp. 9-18.

41. Un informe de la SIDE señalaba que "el peronismo no es la negación del comunismo sino una fase psicológica, ideológica e institucional preparatoria” (Chiarini y Portugheis, 2014: 96-97). 
Frigorífico "Lisandro de la Torre"- ${ }^{42}$ el cierre del periódico La Hora en enero de 1959, la clausura de sus locales y, finalmente, la ilegalización del partido y sus organizaciones el 27 de abril a través del decreto 4.965 en el marco de la huelga bancaria.

Por último, el anuncio del Plan de Estabilización de diciembre de 1958, la puesta en marcha del Plan Conintes y la privatización del mencionado frigorífico en enero de 1959 coincidieron en el tiempo con la Revolución Cubana, razón por la cual marcamos un corte. En primer lugar, la dinámica de la conflictividad sufrió alteraciones: cuantitativamente, en 1959, si bien se alcanzó un pico de jornadas perdidas que se redujo drásticamente en los años siguientes, se interrumpió el proceso de ascenso en número de huelgas iniciado en 1956; ${ }^{43}$ cualitativamente, en ese año no solo se agudizó el contexto represivo, sino que las luchas asumieron un carácter defensivo ante la pérdida de puestos de trabajo y, con la normalización de los sindicatos, se avanzó en el proceso de burocratización de las dirigencias sindicales. En segundo lugar, la Revolución Cubana fue un impacto al poner en agenda la revolución socialista por vía armada en el continente, precisamente cuando la ofensiva del gobierno parecía desmoralizar a los activistas de la Resistencia (James, 2006). No obstante, el principal nudo conflictivo estuvo en el golpe que propinó a las caracterizaciones y el programa del PC la demostración de que el camino al socialismo podía iniciarse sin la resolución de las tareas previas en un país con una estructura económica atrasada dependiente del imperialismo y con "la aplicación de tácticas aventureras" de la guerrilla de Fidel Castro y el Che Guevara. ${ }^{44}$ Se inició así un proceso de discusión estratégica y programática que tuvo en el centro de escena, en el fragmentario campo de las izquierdas, al Partido Comunista.

$$
* * *
$$

En este artículo se examinaron los principales lineamientos políticos y la intervención del PC en el período 1955-1959, caracterizado por la intensificación de la lucha de clases en el contexto de una dictadura y

42. "Informe del Interventor de la UOCRA a la Secretaría de Guerra", Biblioteca Nacional Mariano Moreno. Departamento de Archivos. Fondo Centro de Estudios Nacionales. Subfondo Presidencia Arturo Frondizi.

43. Esto es analizado por James (2006: 166) y Schneider (2005: 132) en base a los datos proporcionados por el Ministerio de Trabajo y Seguridad Social.

44. El PC entendia que el Partido Socialista Popular (partido marxista-leninista en Cuba) debía reunir a las fuerzas democráticas y antiimperialistas para la revolución democrático burguesa. "Cuba", Nueva Era, año X, nº 7, agosto de 1958, pp. 55-64. 
la posterior apertura democrática, ambas atravesadas por el intento de la burguesía por aumentar la productividad del trabajo.

Durante los años analizados, el PC actuó siguiendo el programa definido en los años 30, según el cual la dependencia y el atraso del capitalismo argentino imponian como primera tarea la realización de una revolución democrático-burguesa, relegando a un horizonte indefinido el futuro socialismo. El instrumento determinado para llevar a cabo esa primera tarea fue el FDN, con el que buscaba establecer alianzas no solo con diversos sectores democráticos y antiimperialistas, sino con parte de la burguesía nacional. El PC buscó construir dicho frente sin éxito tanto durante la "Revolución Libertadora" como en las elecciones de 1958. Su esperanza en la imposición del supuesto sector democrático del gobierno de facto se basó en que el fin del llamado "corporativismo-fascista" podría haber significado una capitalización en dos sentidos: una reforma politica que pusiera fin a los personalismos $y$, fundamentalmente, la expectativa por conquistar a la clase obrera peronista. No obstante, nada de eso se materializó y el PC transcurrió esos años como un partido marginado en el plano político nacional y reprimido al calor de la conflictividad social.

Su principal terreno de intervención fue el del movimiento obrero, en donde se abocó, por un lado, a la defensa de las condiciones de vida y de trabajo de la clase obrera en un contexto de racionalización productiva y disminución del salario real y, por otro, a la reorganización del movimiento obrero intervenido. Allí cosechó sus puntos más fuertes guiado por la política unitaria que le permitió acceder al mando de algunos sindicatos importantes y convertirse en el principal armador de un organismo intergremial como la CI.

La lucha de clases a partir de 1955 presentó un rasgo novedoso con el aumento de las acciones violentas, lo cual convivió con la política internacional de coexistencia pacífica pregonada desde Moscú. La ligazón entre el programa democrático enarbolado y la coyuntura del movimiento comunista internacional son elementos centrales para comprender el distanciamiento y la denuncia del PC a los sectores que recurrieron a las mismas, así como su intento por desligar la asociación entre comunismo y subversión.

La moderación táctica y estratégica evidenciada por el PC en este período se revela así como uno de los puntos fuertes a considerar en los análisis en torno a la radicalización política de los años 60, que estuvo atravesada -además de la lesión cubana sobre el reconocido monopolio de la revolución socialista que portaba el PC- por las disidencias con el grupo de intelectuales de Pasado y Presente y La Rosa Blindada y por la enorme fractura en las entrañas de la juventud partidaria que parió al Partido Comunista Revolucionario. 


\section{Bibliografía}

Amaral, S. (2004), "El avión negro: retórica y práctica de la violencia", en S. Amaral y M. Plotkin (comps.), Perón: del exilio al poder, Buenos Aires: Eduntref, pp. 67-88.

Burgos, R. (2004), Los gramscianos argentinos, Buenos Aires: Siglo XXI.

Camarero, H. (2007), A la conquista de la clase obrera. Los comunistas y el mundo del trabajo en la Argentina, 1920-1935, Buenos Aires: Siglo XXI.

- (2014), "Tras las huellas de una ilusión: el Partido Comunista argentino y sus planteos del Frente Democrático Nacional (1955-1963)", Archivos, año III, $\mathrm{n}^{\circ} 5$, pp. 31-50.

Campione, D. (2007), "El Partido Comunista de la Argentina. Apuntes sobre su trayectoria", en E. Concheiro Bórquez, M. Modonesi y H. Crespo (coords.), El comunismo: otras miradas desde América Latina, México: UNAM.

Casola, N. (2015), El PC y la dictadura militar. Militancia, estrategia politica y represión estatal, Colección Archivos, Buenos Aires: Imago Mundi.

Chiarini, S. y E. Portugheis (2014), Plan Conintes. Represión politica y sindical, Buenos Aires: Ministerio de Justicia y Derechos Humanos de la Nación.

Codovilla, V. (1964a), "La nueva relación de fuerzas en lo internacional y nacional y el camino argentino hacia la democracia, la independencia y el socialismo. Informe presentado al CC ampliado del PC. Julio 1956”, en Una trayectoria consecuente en la lucha por la liberación nacional y social del pueblo argentino: trabajos escogidos, tomo 3, Buenos Aires: Anteo, pp 171-277.

Codovilla, V. (1964b), "Por qué Frondizi abandonó el programa del 23 de febrero y aplica el de la oligarquía y el imperialismo. Informe rendido al CC ampliado del PC. 10 y 11 de enero 1959" en Una trayectoria consecuente en la lucha por la liberación nacional y social del pueblo argentino: trabajos escogidos, tomo 3, Buenos Aires: Anteo, pp 370-424.

Gasparri, M. y C. Panella (2008), El congreso normalizador de la CGT de 1957, Buenos Aires: Corregidor.

Gilbert, I. (2009), La Fede, alistándose para la revolución. La Federación Juvenil Comunista, 1921-2005, Buenos Aires: Sudamericana.

Íscaro, R. (1973), Historia del movimiento sindical, tomo II, Buenos Aires: Fundamentos.

James, D. (2006), Resistencia e integración. El peronismo y la clase trabajadora argentina, 1946-1976 [1988], Buenos Aires: Siglo XXI.

Marcou, L. (1981), El movimiento comunista internacional desde 1945, Madrid: Siglo XXI.

Massholder, A. (2013), El Partido Comunista argentino y sus intelectuales: originalidad y marginalidad del pensamiento y acción de Héctor P. Agosti, Buenos Aires: Luxemburg. 
Melon Pirro, J.C. (2009), El peronismo después del peronismo. Resistencia, sindicalismo y politica luego del 55, Buenos Aires: Siglo XXI.

Nadra, A. (2015), Secretos en rojo, Buenos Aires: Corregidor.

Petra, A. (2017), Intelectuales y cultura comunista. Itinerarios, problemas y debates en la Argentina de posguerra, Buenos Aires: Fondo de Cultura Económica.

Piemonte, V. (2013), "El Informe Secreto al XX Congreso del Partido Comunista de la Unión Soviética en la perspectiva oficial del Partido Comunista Argentino. Recepción y primeras repercusiones", Anuario del Centro de Estudios Históricos "Prof. Carlos S. A. Segreti", año 13, n 13, Córdoba, pp. 223-241.

Portantiero, J.C. (1977), "Economía y política en la crisis argentina (19581973)", Revista Mexicana de Sociología, vol. 39, n 2, pp. 531-565.

Prado Acosta, L. (2015), Los intelectuales del Partido Comunista: Itinerario de Héctor Agosti (1930-1963), Raleigh: A Contracorriente.

Rot, G. (2007), "El Partido Comunista y la lucha armada", Lucha Armada, $\mathrm{n}^{\circ}$ 7, Buenos Aires, pp. 14-25.

Salas, E. (1990), La resistencia peronista: la toma del frigorifico Lisandro de la Torre, Buenos Aires: CEAL.

Schneider, A. (2005), Los compañeros. Trabajadores, izquierda y peronismo, 1955-1973, Buenos Aires: Imago Mundi.

Senén González, S. (1971), El sindicalismo después de Perón, Buenos Aires: Galerna.

Spinelli, M.E. (2005), Los vencedores vencidos. El antiperonismo y la "revolución libertadora", Buenos Aires: Biblos.

Staltari, S. (2014), "El Partido Comunista frente al peronismo: estrategia y tácticas políticas. 1945-1955”, Archivos, año III, nº 5, pp. 11-30.

Tortti, M.C. (1999), "Izquierda y "nueva izquierda" en la Argentina. El caso del Partido Comunista", Sociohistórica, n 6, pp. 221-232. 